OPEN ACCESS

Edited by:

Salvatore Arpaia,

Italian National Agency for New Technologies, Energy and Sustainable Economic Development (ENEA), Italy

Reviewed by:

Rob Morrison,

United States Department of Agriculture, United States Madelaine Venzon, Agronomical Research Institute of

Minas Gerais, Brazil

*Correspondence:

Johnattan Hernández-Cumplido johnattanhdez@ciencias.unam.mx

${ }^{\dagger}$ These authors share first authorship

Specialty section

This article was submitted to

Pest Management

a section of the journa

Frontiers in Agronomy

Received: 12 October 2020 Accepted: 08 December 2020

Published: 05 January 2021

Citation:

Hernández-Cumplido J,

Rodriguez-Saona $C$

Ruíz-Rodríguez CE, Guevara-Fefer $P$, Aguirre-Paleo S, Miranda Trejo S and

Callejas-Chavero A (2021) Genotypic Variation in Plant Traits, Chemical

Defenses, and Resistance Against Insect Herbivores in Avocado (Persea americana) Across a Domestication

Gradient. Front. Agron. 2:616553.

doi: 10.3389/fagro.2020.616553

\section{Genotypic Variation in Plant Traits, Chemical Defenses, and Resistance Against Insect Herbivores in Avocado (Persea americana) Across a Domestication Gradient}

\author{
Johnattan Hernández-Cumplido ${ }^{1 * t}$, Cesar Rodriguez-Saona ${ }^{2 \dagger}$, \\ Claudia E. Ruíz-Rodríguez ${ }^{1}$, Patricia Guevara-Fefer ${ }^{1}$, Salvador Aguirre-Paleo ${ }^{3}$, \\ Serafín Miranda Trejo ${ }^{3}$ and Alicia Callejas-Chavero ${ }^{4}$
}

' Departamento de Ecología y Recursos Naturales, Facultad de Ciencias, Universidad Nacional Autónoma de México, Ciudad de México, Mexico, ${ }^{2}$ P. E. Marucci Center for Blueberry and Cranberry Research and Extension, Rutgers University, Chatsworth, NJ, United States, ${ }^{3}$ Facultad de Agrobiología Presidente Juárez, Universidad Michoacana de San Nicolás de Hidalgo, Uruapan, Mexico, ${ }^{4}$ Laboratorio Ecología Vegetal, Departamento de Botánica, Escuela Nacional de Ciencias Biológicas, IPN, Ciudad de México, Mexico

Domestication promotes divergence between wild and cultivated plants. The "plant domestication-reduced defense" hypothesis proposes that cultivated plants have lower chemical defenses and resistance against herbivores than their wild counterparts. Yet, the effects of domestication on the interactions between perennial crops and insect herbivores have not been well-documented. In this study, we hypothesized that domesticated avocado (Persea americana) has lowered resistance against insect herbivores. To test this hypothesis, we measured variation in plant traits (fruit and seed size, seed germination, and plant growth), chemical defenses (total phenolics), and resistance against two leaf-chewing insect herbivores - a specialist (Copaxa multifenestrata) and a generalist (Spodoptera frugiperda)-among seven avocado genotypes across a domestication gradient: wild (ancestral) genotypes, five (intermediate) landraces ("Blanco," "Lonjas," "Vargas," "Zarcoli," and "Rodolfo"), and the cultivated (modern) "Hass." Our results showed that seeds from "Hass" have a lower germination rate and slower growth and have shorter fruits and seeds than the landraces and wild genotypes. "Hass" leaves also had lower amounts of total phenolics than the landraces; however, no differences were found between "Hass" and the wild genotypes. There was no effect of genotype on larval mass gained for both herbivores. However, C. multifenestrata had longer larval longevity on "Hass" and the wild genotypes, whereas S. frugiperda larval longevity showed no differences among genotypes. Moreover, C. multifenestrata inflicted more damage on "Hass," whereas S. frugiperda inflicted more damage on "Lonjas" than on the other genotypes. In general, bigger fruit and seeds were positively correlated with plant size and phenolic content, and total phenolics were positively correlated with S. frugiperda and negatively correlated with C. multifenestrata 
larval performance. However, despite the genotypic variation in plant traits, phenolic content, and resistance against two herbivores with different levels of specialization, there was no clear support for the "plant domestication-reduced defense" hypothesis in avocado.

Keywords: plant domestication-reduced defense hypothesis, perennial, generalist, specialist, plant traits

\section{INTRODUCTION}

One of the main goals of crop domestication is the selection of traits important for human consumption such as an increase in harvestable yields (Whitehead and Poveda, 2019); however, this selection often generates unintentional changes on plant traits linked to morphology, nutrient content, and secondary metabolites (Evans, 1993). For example, crop domestication often results in simpler plant morphologies, alteration of the plant's nutritional content, and reduction in plant defenses (Smartt and Simmonds, 1995; Lindig-Cisneros et al., 1997; Jones, 1998; Gols et al., 2008; Whitehead et al., 2017).

Although evidence of the effects of domestication on insect herbivores has accumulated during the last 30 years, there are still gaps in our knowledge. As proposed by the "plant domesticationreduced defense" hypothesis (Gaillard et al., 2018; HernandezCumplido et al., 2018), there is a general assumption that domestication reduces plant defenses (Wink, 1988; Rosenthal and Dirzo, 1997; Benrey et al., 1998; Rodriguez-Saona et al., 2011) due to potential trade-offs between plant defense and reproduction (Rhoades, 1979; Rosenthal and Dirzo, 1997). However, plant responses to domestication are variable and depend mainly on the structure under selection and the approach that researchers use to evaluate resistant traits (Whitehead et al., 2017). Coupled with this evidence, our current knowledge on the effects of domestication on plant-insect interactions mostly comes from research on short-lived annual plants and a reduced set of plant species (mainly Poaceae) (Miller and Gross, 2011; Meyer et al., 2012). So far, little information has been generated on this topic regarding perennial plants. Three predictions have been raised for perennial plants under artificial selection: (1) the negative effects of domestication on plant resistance and defense will be weakest for woody perennials, intermediate for herbaceous perennials, and strongest for herbaceous annuals; (2) annual plants will show faster rates of evolution than perennial plants due to their short lifespan and development and also because most of the annual crops are grown from seeds, whereas more than $75 \%$ of perennial plants are clonally propagated; and (3) selection to maintain natural defenses should be higher in perennial plants because practices such as crop rotation are not possible for these plants (Miller and Gross, 2011; Meyer et al., 2012; Whitehead et al., 2017).

Recently, comparative studies investigated the effects of crop domestication on herbivores with different evolutionary histories with the host plant (Gaillard et al., 2018; RodriguezSaona et al., 2019) and from different feeding guilds (Turcotte et al., 2014; Hernandez-Cumplido et al., 2018). Turcotte et al. (2014) compared the effect of the domestication process along
29 herbaceous crop species on two generalist herbivores with different feeding habits (sap sucking v/s chewing) and found a negative effect of domestication on the resistance against a chewing herbivore (Spodoptera exigua Hübner), whereas no effect of domestication was observed for a sap-sucking herbivore (Myzus persicae Sulzer). Gaillard et al. (2018) found a stronger reduction in the performance of generalist than specialist herbivore species on wild plants (teosinte) compared to cultivated maize lines. Similarly, Hernandez-Cumplido et al. (2018) found that the effect of domestication depends on herbivore identity in the North American perennial crop highbush blueberry (Vaccinium corymbosum L.), such that the invasive chewing herbivore Lymantria dispar $\mathrm{L}$. performed better on domesticated plants compared to wild plants, whereas no effects were found for the native chewing herbivore Sparganothis sulfureana (Clemens). In general, these studies reflect the need to investigate the role of herbivore species identity to get a better understanding of the effects of domestication on plant defenses and herbivore resistance.

Avocado, Persea americana Mill. (Lauraceae), is one of the most important crops produced in Mexico that is currently widely distributed around the world (Ashworth et al., 2011; Pérez Álvarez et al., 2015). This perennial crop originated in the New World, and archeological evidence suggests that it has been under human selection since 5,000 BC (Galindo-Tovar et al., 2008; Landon, 2009). In Mexico, at least two plant traits have been under artificial selection in avocado, depending on the region. In coastal states, like Oaxaca and Guerrero, leaves are used as condiments and people select for the "anise" smell of some leaves. Another trait under selection has been the size and flavor of the fruit. In the state of Michoacan (Mexico), the highest producer of avocado with $38 \%$ of the world's production (SAGARPA, 2011), avocado orchards (mainly var. "Hass") are found mixed with pine oak forest. Inside these orchards, different landraces and wild plants are left by the farmers to obtain seeds for the establishment of rootstock to graft "Hass" branches. The avocado leaves, seeds, and peel are rich in bioactive molecules, such as phenolic compounds (Yamassaki et al., 2017), which are compounds generally involved in plant defense against insect herbivores (Harborne, 2000; Mithöfer and Boland, 2012). These compounds are often found in lower amounts in cultivated plants, including blueberries (Vaccinium spp.) (Giovanelli and Buratti, 2009), murtilla (or Chilean guava; Ugni molinae Turcz) (Chacón-Fuentes et al., 2015), several other berries (MikulicPetkovsek et al., 2012), and Opuntia spp. (Astello-García et al., 2015), than in their wild counterparts.

In this study, we measured variation in reproductive and growth traits (seed and fruit size, seed germination, and 
plant growth), chemical defenses (phenolic compounds), and resistance against two leaf-chewing insect herbivores with different degrees of host specialization among seven avocado genotypes selected across a domestication gradient: a wild (ancestral) genotype, five (intermediate) landraces ("Blanco," "Lonjas," "Vargas," "Zarcoli," and "Rodolfo"), and the cultivated (modern) genotype "Hass." Based on the plant domesticationreduced defense hypothesis, we predicted higher chemical defenses and resistance against herbivores in the wild avocado genotype, intermediate resistance among landraces, and the lowest resistance in the modern cultivated genotype. Our specific goal was to investigate whether domestication of avocado changed reproductive/growth traits and chemistry (phenolic compounds) and its effects on the performance of two herbivores with different coevolutionary histories with the crop. The generalist fall armyworm (Spodoptera frugiperda Smith; Lepidoptera, Noctuidae) is considered a secondary pest of avocado (Montezano et al., 2018), and the avocado moth (Copaxa multifenestrata Heinrich-Shaffer; Lepidoptera, Saturniidae) is a specialist on avocado (Moreno et al., 2010; Perez-Salgado et al., 2016). We expected that (1) trade-offs exist between reproductive/growth traits and resistance against herbivores; (2) chemical defenses have decreased due to the domestication of avocado and, as a result, its resistance against herbivores; and (3) the effects of domestication on herbivores depend on their degree of host specialization such that these effects should be stronger on the generalist than on the specialist herbivore species.

\section{MATERIALS AND METHODS}

\section{Field Sites and Plant Genotypes}

All sampled sites were located in Tacambaro (Michoacan State, Mexico; $19^{\circ} 25^{\prime} \mathrm{N}, 19^{\circ} 06^{\prime} \mathrm{S}$, and $101^{\circ} 38^{\prime} \mathrm{E}$ ), which is part of the "avocado belt"-the main zone of avocado production in Mexico (Medina-Aguilar et al., 2011). Fruit samples were collected from a commercial farm (Testerazo farm; $19^{\circ} 15^{\prime} 33.1^{\prime \prime} \mathrm{N}, 101^{\circ} 27^{\prime} 39.9^{\prime \prime}$ $\mathrm{W}$ ) in August 2017. All plants were at least 10 years old. Ripe fruits from seven avocado genotypes, including one wild (ancestral) genotype, five (intermediate) landraces ("Blanco," "Lonjas," "Vargas," "Zarcoli," and "Rodolfo"), and the cultivated (modern) genotype "Hass," were collected. A single fruit was taken per tree, and trees were separated at least $100 \mathrm{~m}$ from each other. Because fruit samples from wild plants were taken from three distinct sites (W1, W2, and W3) located at least $2 \mathrm{~km}$ apart, fruits from each of these sites were considered subpopulations and thus kept separately. The number of fruits collected was as follows: $\mathrm{W} 1=7, \mathrm{~W} 2=8, \mathrm{~W} 3=10$, "Lonjas" $=10$, "Vargas" = 10 , "Zarcoli" = 10, "Blanco" = 10, "Rodolfo" = 11, and "Hass" = 10 , for a total of 86 fruits. All field-collected fruits were brought to the laboratory on the same day of collection (20 August 2017).

\section{Plant Propagation and Traits}

At the laboratory in the Universidad Nacional Autónoma de México (Mexico City, Mexico), the length and width of fruits were measured. After being removed from fruits, seeds were carefully washed, and their length and width were recorded. Seeds were then brought to a greenhouse $\left[22 \pm 2{ }^{\circ} \mathrm{C}, 50 \pm 10 \%\right.$ relative humidity $(\mathrm{RH}), 12: 12$ light:dark (L:D)] and planted in 5$\mathrm{L}$ pots with a premixed dirt (Vigoro Industries Inc.; Honolulu, HI, USA), watered every 3 days, and fertilized twice with 20 20-20 N-P-K all-purpose water-soluble food (Scotts Miracle-Gro Products, Inc.; Port Washington, NY, USA). Percent germination was recorded after 8 weeks, and seedling growth was measured monthly for 4 months. After 10 and 12 months, these plants were used for insect performance studies and phenolic analysis, respectively (see below).

\section{Insect Rearing}

A S. frugiperda colony was initiated in 2017 from eggs obtained from maize fields near Mexico City (Mexico), and new eggs collected from the same field sites were added to the colony every 2 months to prevent inbreeding. In the laboratory, S. frugiperda larvae were maintained on a wheat germ-based diet (Magnoler, 1970). A C. multifenestrata colony was also initiated in 2017 from larvae collected from avocado landraces located in the city of Chilpancingo in Guerrero (Mexico). The C. multifenestrata larvae were maintained on "Hass" leaves until adult emergence; these adults were then allowed to lay eggs, and larvae from this generation were used in experiments. Spodoptera frugiperda larvae were reared individually in $29.7-\mathrm{ml}$ plastic cups, whereas C. multifenestrata larvae were maintained together in a Rearing \& Observation Cage $(61 \times 61 \times 91.4 \mathrm{~cm}$; BioQuip Products; Rancho Dominguez, CA, USA). All colonies were maintained at $25 \pm 1{ }^{\circ} \mathrm{C}, 70-80 \% \mathrm{RH}$ and a $16: 8 \mathrm{~h}$ (L:D) photoperiod.

\section{Phenolic Analysis}

After 12 months, we selected a subset of plants from each genotype (number of plants: wild genotype $=7$, "Blanco" $=3$, "Zarcoli" = 3, "Lonjas" = 3, "Vargas" $=6$, "Rodolfo" $=3$, and "Hass" = 10) for phenolic analysis. Leaves (3-4) were collected from each plant and oven-dried for $48 \mathrm{~h}$ at $40^{\circ} \mathrm{C}$. The leaf material was then ground with liquid nitrogen to obtain a homogenous powder. We took $0.5 \mathrm{~g}$ of the leaf powder and dissolved it in $70 \%$ acetone at a $1: 30(\mathrm{gm} / \mathrm{L})$ ratio. The solution was placed in an ultrasonic bath for $90 \mathrm{~min}$. Samples with the solvent were vacuum filtered using a Buchner funnel with 70-mm Whatman filter paper (Sigma Aldrich, St. Louis MO, USA) and washed with acidified acetone three times. The phenolic solution was poured into a separatory funnel with 1.5 volumes of chloroform. The chloroform/phenolic solution was mixed and then left at room temperature $\left(\sim 20^{\circ} \mathrm{C}\right)$ for $8 \mathrm{~h}$ to allow separation. The bottom chloroform layer was discarded, and the top of the polar layer was collected. Residues of acetone were removed by evaporation using a Rotavapor (Buchi Co., New Castle, DE, USA). Total phenolics were determined colorimetrically by the Folin-Ciocalteu method in a BioRad 650 microplate reader at $740 \mathrm{~nm}$ and using gallic acid as the standard (Makkar, 2003). Total phenolics are expressed in $\mu \mathrm{g} / \mathrm{g}$ of dry mass tissue.

\section{Insect Performance}

Insect performance studies were conducted in the greenhouse $\left(22 \pm 2^{\circ} \mathrm{C}, 50 \pm 10 \% \mathrm{RH}, 12: 12 \mathrm{~L}: \mathrm{D}\right)$ in August-September of 2018. For the generalist $S$. frugiperda, five 3 rd instars were placed inside clip cages $(60 \times 15 \mathrm{~mm})$, whereas for the specialist $C$. 
multifenestrata, three 2nd instars were placed per clip cage, and three clip cages were placed per plant $(N=15$ and 9 larvae per plant of S. frugiperda and C. multifenestrata, respectively). Although multiple larvae were placed in each clip cage to ensure sufficient leaf damage, no evidence of cannibalism among larvae was observed. The total number of plants used for the specialist herbivore was three wild genotypes, two "Lonjas," three "Rodolfo," three "Blanco," three "Vargas," three "Zarcoli," and three "Hass" ( $N=20$ plants). For the generalist herbivore, we used four wild genotypes, three "Lonjas," three "Rodolfo," three "Blanco," three "Vargas," four "Zarcoli," and four "Hass" ( $N=$ 24 plants).

Before the experiment and after 11 days of feeding, all surviving larvae were weighed using an analytical balance (EP220A; $0.01 \mathrm{mg}$ sensitivity; Precisa, Tuttlingen, Germany). After 11 days, larval mass gained (obtained by subtracting the initial mass from the final mass) and the amount of leaf consumed by larvae were determined. Leaf area consumed was measured using the BioLeaf mobile app (Machado et al., 2016). Because larval survival of both herbivores was unexpectedly low $(<20 \%)$, we report instead larval longevity, i.e., the total number of days that the larvae survived. Thus, larval mass and longevity and leaf consumption were calculated for each clip cage and were used as measures of insect performance and plant resistance.

\section{Statistical Analysis}

Statistical analysis was performed on JMP version 10 (SAS Institute Inc.; Cary, NC, USA). Before analysis, all data (for plant traits, phenolics, and insect performance) were averaged per plant (replicate). Because data on fruit and seed length and width met assumptions of normal distribution and homogeneity of variances, we used one-way analysis of variance (ANOVA) to assess differences among genotypes, followed by multiple comparison Tukey's honestly significant difference (HSD) test.

We performed $\chi^{2}$ tests to compare differences in percent germination among avocado genotypes. Two-way ANOVA was used to test for differences in seedling growth among avocado genotypes at different time periods (date) and the interaction between genotype and date. A significant ANOVA was followed by multiple comparison Tukey's HSD test. Data on seedling growth were $\log (\mathrm{x}+1)$-transformed to meet assumptions of normal distribution.

Data for total phenolics met the assumptions of normal distribution, so we performed one-way ANOVA, followed by a multiple comparison Tukey's HSD test. Data on mass gained by herbivore larvae did not meet the assumption of normality even after transformation and were thus analyzed using generalized linear mixed models (GLMMs) with a Poisson distribution and a log-link function. For C. multifenestrata larval longevity, data were analyzed by generalized linear model (GLM) with a normal distribution and identity-link function. For S. frugiperda larval longevity and leaf area consumed, data were analyzed by GLMM with a Poisson distribution and a log-link function because data did not meet the assumptions of normality even after transformation.

To test for potential trade-offs in avocado between reproduction, growth, and resistance traits, we conducted a series of linear correlations between the measured plant reproductive (seed and fruit size) and growth (plant size) traits, defensive compounds (phenolics), and insect performance parameters (larval longevity, larval mass gained, and leaf consumption).

\section{RESULTS}

\section{Plant Traits}

We found significant differences in fruit length $(F=48.24$; $\mathrm{df}=8,85 ; P<0.001)$ and width $(F=71.72 ; \mathrm{df}=8,85$; $P<0.001)$ among avocado genotypes. The wild and "Hass" genotypes had lower fruit length than the landraces (Figure 1A). However, "Hass" fruit were the widest of all genotypes, and the wild genotypes had the lowest width (Figure 1B).

There were also significant differences in seed length $(F=$ $39.35 ; \mathrm{df}=8,85 ; P<0.001)$ and width $(F=9.38$; $\mathrm{df}=8,85$; $P<0.001)$ among avocado genotypes. Similar to fruit length, "Hass" seeds had the lowest length, followed by wild genotypes, and landraces tended to have the highest seed length (Figure 1C). In contrast, seeds of the cultivated "Hass" tended to be the widest of all genotypes, whereas the seeds of the wild genotypes tended to have the lowest width; seeds of the landraces tended to be intermediate between wild and cultivated genotypes (Figure 1D).

Percent seed germination also differed among avocado genotypes $\left(\chi^{2}=15.73 ; \mathrm{df}=8 ; P=0.046\right)$. On average, the landraces had the highest germination rates ("Blanco" $=80 \%$, "Lonjas" $=60 \%$, "Vargas" $=100 \%$, "Zarcoli" $=70 \%$, and "Rodolfo" $=55 \%$ ), followed by the wild genotypes (W1 $=43 \%$, $\mathrm{W} 2=38 \%$, and $\mathrm{W} 3=70 \%$ ), whereas the cultivar "Hass" had the lowest germination rate at $10 \%$. For seedling growth (i.e., size of plants), we found significant effects of genotype $(F=12.10$; $\mathrm{df}=$ 8, 343; $P<0.001)$, date $(F=75.79 ; \mathrm{df}=3,343 ; P<0.001)$, and the interaction between genotype and date $(F=2.544 ; \mathrm{df}=24$, $343 ; P=0.011$ ) (Figure 2). Although there were some differences by month, in general, the wild genotypes and the cultivar "Hass" had lower growth rates than the landraces, with "Vargas" having the highest growth rate among them.

\section{Phenolics}

There were significant differences in the levels of total phenolics among avocado genotypes $(F=5.279 ; \mathrm{df}=6,34 ; P=0.001)$. The landrace "Zarcoli" had the highest levels of total phenolics, whereas the landrace "Vargas" and the cultivar "Hass" had the lowest levels of total phenolics (Figure 3).

\section{Insect Performance}

For the generalist $S$. frugiperda, we found no significant differences in larval longevity among avocado genotypes $(F=$ 0.72 ; $\mathrm{df}=6,23 ; P=0.63$; Figure $4 \mathrm{~A})$. There were also no differences in larval mass gained among genotypes $\left(\chi^{2}=0.35\right.$; $\mathrm{df}$ $=6 ; P=0.99)$. However, there were differences in the amount of foliar damage among genotypes $\left(\chi^{2}=98.67 ; \mathrm{df}=6 ; P<0.001\right)$. The landrace "Lonjas" suffered significantly more damage by $S$. frugiperda larvae than the landrace "Rodolfo" and the cultivar "Hass" (Figure 4B).

For the specialist $C$. multifenestrata, there were significant differences in larval longevity among avocado genotypes $(F=$ 
A

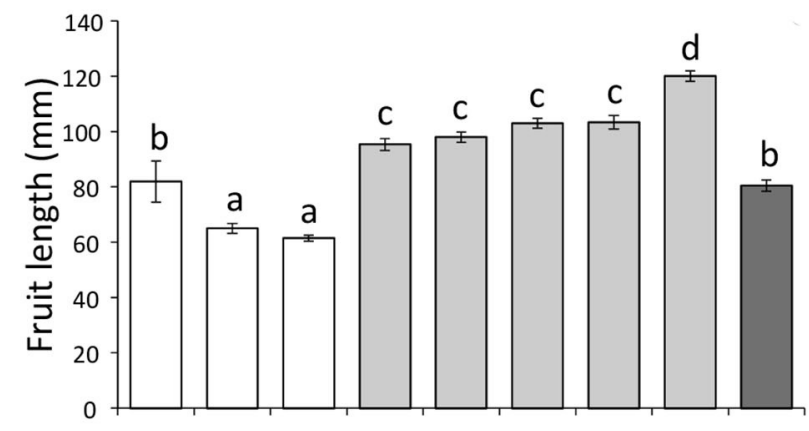

C

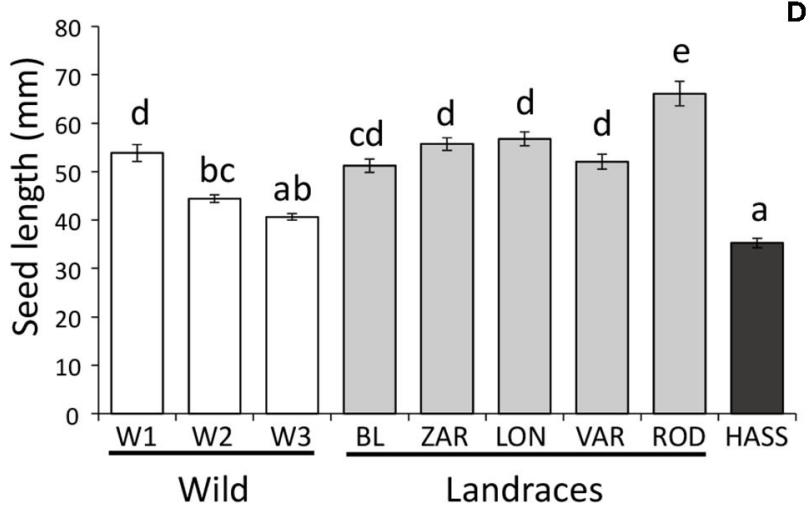

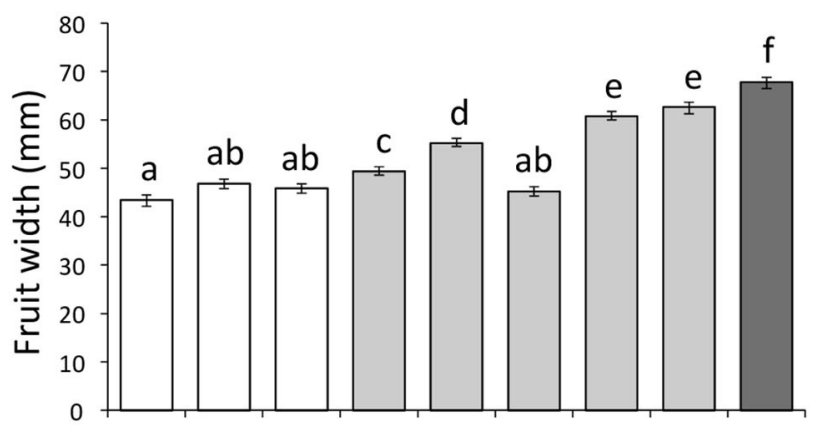

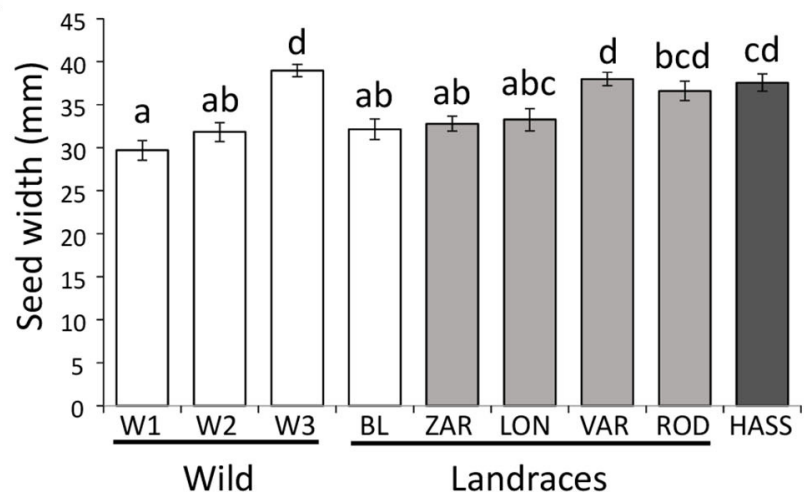

FIGURE 1 | Avocado (Persea americana) reproductive trait variation of different genotypes across a domestication gradient on (A) fruit length, (B) fruit width, (C) seed length, and (D) seed width. White bars = wild (ancestral) genotypes; gray bars = landraces (intermediate); dark bar = cultivated (modern) "Hass" variety. W1-W3 = wild populations 1-3; landraces: $\mathrm{BL}=$ "Blanco," LON = "Lonjas," ZAR = "Zarcoli," VAR = "Vargas," and ROD = "Rodolfo." Bars are means \pm SE per fruit. Different letters indicate significant differences among genotypes $(P \leq 0.05)$, according to Tukey's HSD post-hoc tests.

3.85; df $=6,19 ; P=0.019)$. Larval longevity was highest in the landrace "Vargas" and the cultivar "Hass" and lowest in the landrace "Lonjas" (Figure 5A). Although we found no differences in larval mass gained among avocado genotypes $\left(\chi^{2}=0.06\right.$; $\mathrm{df}$ $=6 ; P=1.00)$, there were differences in the amount of foliar damage among genotypes $(F=11.67$; $\mathrm{df}=6,19 ; P<0.001)$. Larvae inflicted higher foliar damage on the cultivar "Hass" than the landraces "Blanco," "Zarcoli," and "Lonjas" (Figure 5B).

\section{Correlations Among Plant Reproductive, Growth, and Resistance Traits}

As expected, we found a significant positive correlation between the size of fruit and the size of seeds (Table 1). Larger and wider fruit had larger and wider seeds. There was, however, no correlation between the length of fruit and the width of seeds and vice versa, such that longer fruit were not necessarily wider. Plant size was positively correlated with fruit and seed length but not with fruit and seed width (Table 1), indicating that larger fruit/seeds produced bigger plants.

Total phenolics were positively correlated with seed length (Table 1). No other plant reproductive/growth trait was correlated with total phenolics. We also found a positive correlation between total phenolics and the mass gained by the generalist $S$. frugiperda (Table 1), indicating that the larval performance of this generalist herbivore was enhanced by increased phenolic levels in avocado leaves. In contrast, we found significant negative correlations between total phenolics and the survival of, and amount of foliar damage by, the specialist $C$. multifenestrata (Table 1), indicating that the larval performance of this specialist herbivore was reduced by increased phenolic levels in avocado leaves.

\section{DISCUSSION}

Studies on the effects of crop domestication on herbivore resistance have increased in the last 20 years (Chaudhary, 2013; Chen et al., 2015; Whitehead et al., 2017); yet, more studies using perennial plants are needed for a broader understanding of these effects (but see Rodriguez-Saona et al., 2011; Chacón-Fuentes et al., 2015; Whitehead et al., 2017; Hernandez-Cumplido et al., 2018; Whitehead and Poveda, 2019). In our study, we tested how domestication has affected plant traits and resistance in avocado across a domestication gradient. In general, we demonstrated that wild avocado and the cultivated (modern) "Hass" avocado have smaller fruit and seed, lower growth rates, and lower total phenolics than the intermediate landraces. Accordingly, smaller fruit resulted in smaller plants with lower total phenolics. This variation in plant traits affected resistance to insect herbivores in 


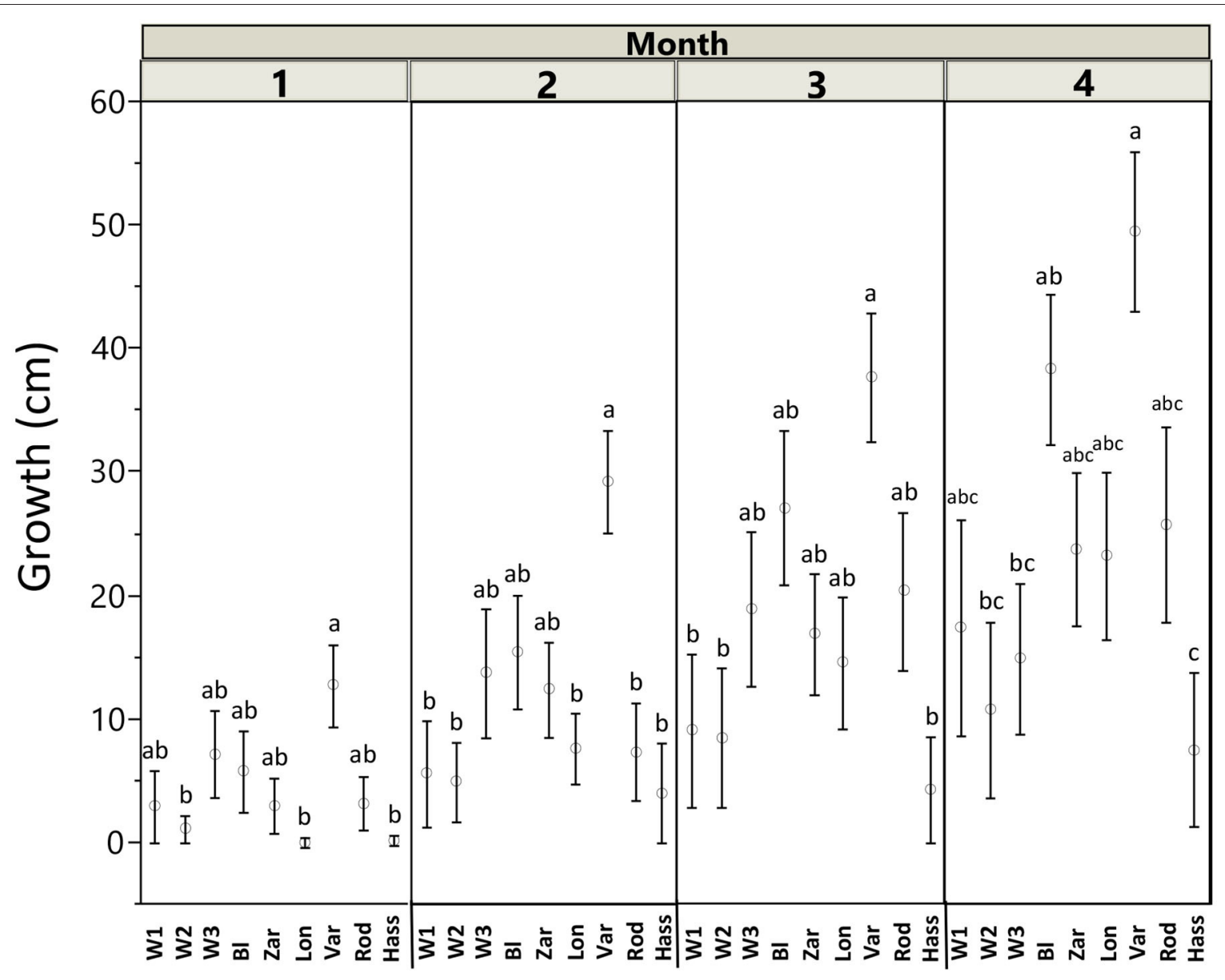

FIGURE 2 | Avocado (Persea americana) growth trait variation by genotype across a domestication gradient. Data points represent the size (means \pm SE) of plants throughout 4 months. W1-W3 = wild populations 1-3; landraces: BL = "Blanco," LON = "Lonjas," ZAR = "Zarcoli," VAR = "Vargas," and ROD = "Rodolfo." Different letters within each month indicate significant differences among genotypes $(P \leq 0.05)$, according to Tukey's HSD post-hoc tests.

unpredictable ways-we found that the generalist S. frugiperda generally performed better in the landraces, whereas the opposite was true for the specialist C. multifenestrata. Thus, our findings provide no clear support for the "plant domestication-reduced defense" hypothesis in avocado.

\section{Avocado Domestication on Reproductive/Growth Traits}

The "domestication syndrome" refers to the distinct phenotypic differences in morphological and physiological traits between wild progenitors and their cultivated descendants (Koinange et al., 1996; Gepts, 2004; Brown et al., 2009). In this study, we found marked phenotypic differences in growth and reproductive traits between wild and domesticated (landraces and modern) avocado, thus providing the first evidence for a domestication syndrome in this perennial crop. However, there were two opposing paths on the effects of domestication in avocado growth and reproductive traits.

In general, the avocado landraces included in this study have bigger fruit and seed size, which resulted in bigger plants. Indeed, plant size was positively correlated with the size of fruit and seeds, indicating a lack of trade-off between investment in growth and reproduction. One of the landraces, "Rodolfo," had the biggest fruit and seeds, which, according to farmers, was one of the most consumed and commercialized landraces in Mexico prior to the 1960 s when "Hass" became popular. In fact, since "Hass" dominated the international market, the landraces have lost their economic value and are now distributed only in local markets (Reyes-Alemán et al., 2009). As a result, farmers have stopped expanding their cultivation and prefer to use them as grafts for "Hass." These landraces were subjected to early selection by local farmers, which contributed to the diversity in fruit sizes observed today and indicated that avocado domestication has occurred without losses of genetic diversity (Jardon-Borbolla et al., 2013). To the contrary, since there was great variation across domesticated (landraces and modern) genotypes in agronomic and resistance traits, our study shows that avocado domestication might have contributed to an increase in its genetic diversity.

Contrary to our expectations, the cultivated (modern) "Hass" has smaller fruit and seed size than the landraces, and these 


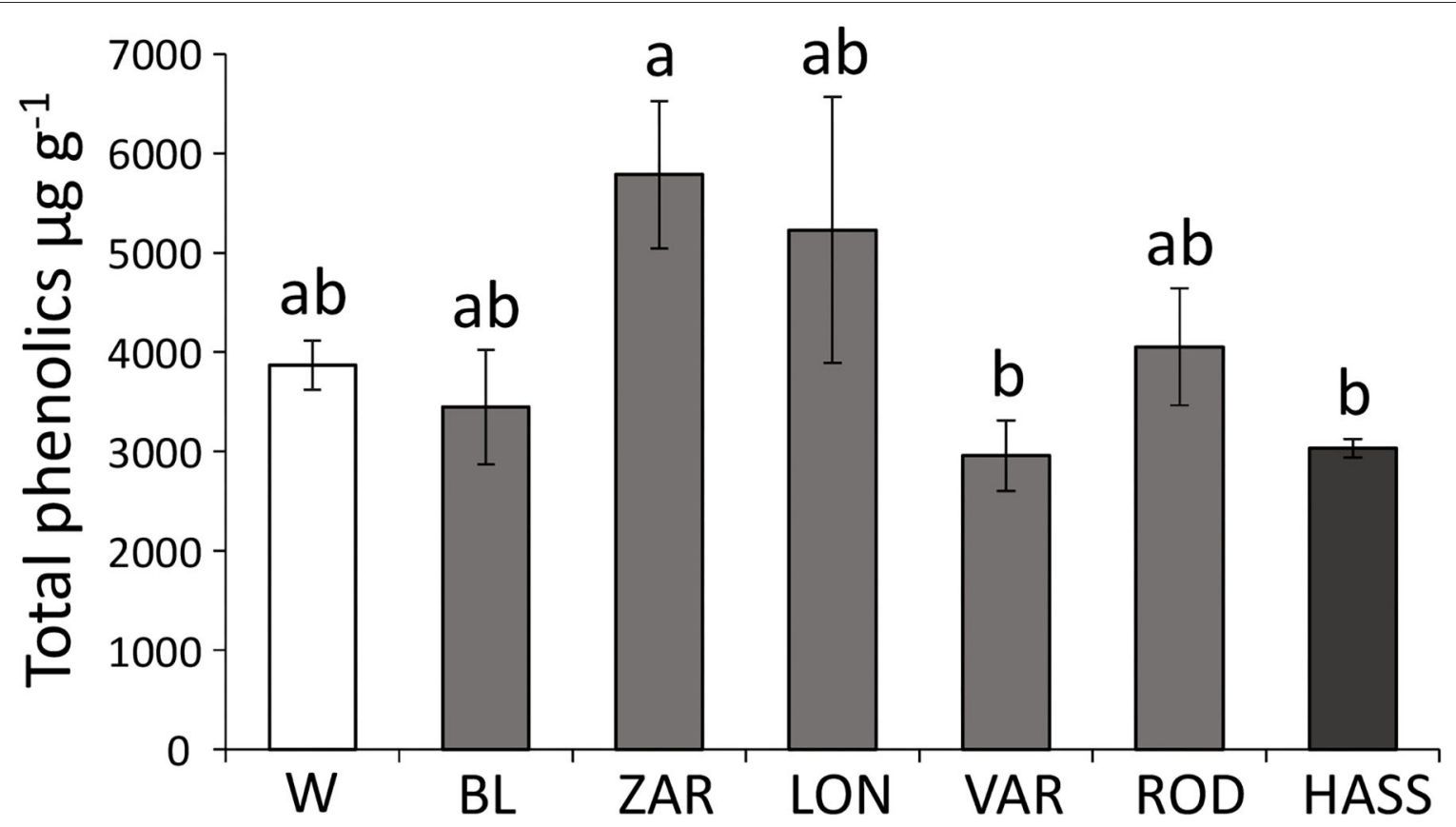

FIGURE 3 | Amounts of total phenolics in avocado (Persea americana) leaves by genotype across a domestication gradient. $\mathrm{W}=$ wild genotypes; landraces: $\mathrm{BL}=$ "Blanco," LON = "Lonjas," ZAR = "Zarcoli," VAR = "Vargas," and ROD = "Rodolfo." Bars are means ( $\mu$ g/g) \pm SE. Different letters indicate significant differences among genotypes $(P \leq 0.05)$, according to Tukey's HSD post-hoc test.

measures were comparable to those of the wild genotypes. "Hass" also has a slow growth rate and low germination, showing a limitation to allocate resources to growth and survival. These results indicate that seed size is an important determinant of plant germination and growth, as shown in cereals and grain legumes (Abbo et al., 2014). Although it needs confirmation, cultivated "Hass" avocados might perform better under agronomic conditions of high fertility and irrigation than in natural environments common to the wild and landrace genotypes, as has been proposed for domesticated maize (Gepts, 2004). Therefore, it seems that perennial crops like avocado may experience some of the same effects of domestication as annual crops. Although most crops are bred for larger fruit and bigger plants, a syndrome referred to as "gigantism" (Evans, 1993; Koinange et al., 1996; Gepts, 2004; Bautista et al., 2012), this was not necessarily the case for avocado. Instead, the small size of "Hass" fruit might have been selected for easier handling and packaging, which requires more circular fruit according to the Mexican Standard for Exportation NMX-FF-016-2002 (Proaguacate, 2010). Moreover, "Hass" avocados are subjected to long distance trade, and producers have the anecdotical belief that the likelihood of rotting increases when fruits are bigger or have a higher amount of pulp; thus, it is better to breed for small fruit size to avoid losses during transportation due to diseases.

\section{Avocado Domestication on Resistance Traits}

Two methods were used to measure resistance in avocados. First, we measured total phenolics in leaves. Second, we conducted larval performance bioassays with two herbivores, a specialist on avocados (C. multifenestrata) and a generalist (S. frugiperda). Theories on plant allocation to defenses predict constrains by a trade-off between growth and defense such that slow-growing plants usually have higher levels of secondary metabolites, such as phenolics, than faster-growing ones, as stated by the "resourceavailability" (Coley et al., 1985) and the "growth differentiation balance" (Herms and Mattson, 1992) hypotheses. Thus, it is possible that the selection for increased yield and growth rate that occurs when plants are domesticated may cause a reduction in allocation to secondary metabolites (Rosenthal and Dirzo, 1997; Jones, 1998; Massei and Hartley, 2000; Meyer et al., 2012), but this pattern is not consistent across all crops (Turcotte et al., 2014; Whitehead et al., 2017). In avocado, our phenolic analysis revealed that these compounds are generally higher in landraces, intermediate in wild genotypes, and lowest in the cultivated "Hass," which indicates a divergent effect of avocado domestication on phenolic content. Therefore, even within a crop, the effects of domestication on secondary metabolites might not be consistent and may depend on the plant organ under selection. We also found a positive correlation between seed size (i.e., length) and total phenolic content, indicating a lack of tradeoff between reproductive/growth investment and defense in this crop. We only measured total phenolics in this study; future studies are needed to determine if other secondary metabolites are similarly affected by domestication in avocado.

There were strong effects of the genotypic variation in avocado on resistance against insect herbivores. The theory on plant defenses predicts that specialist herbivores should 


\section{A \\ Spodoptera frugiperda}

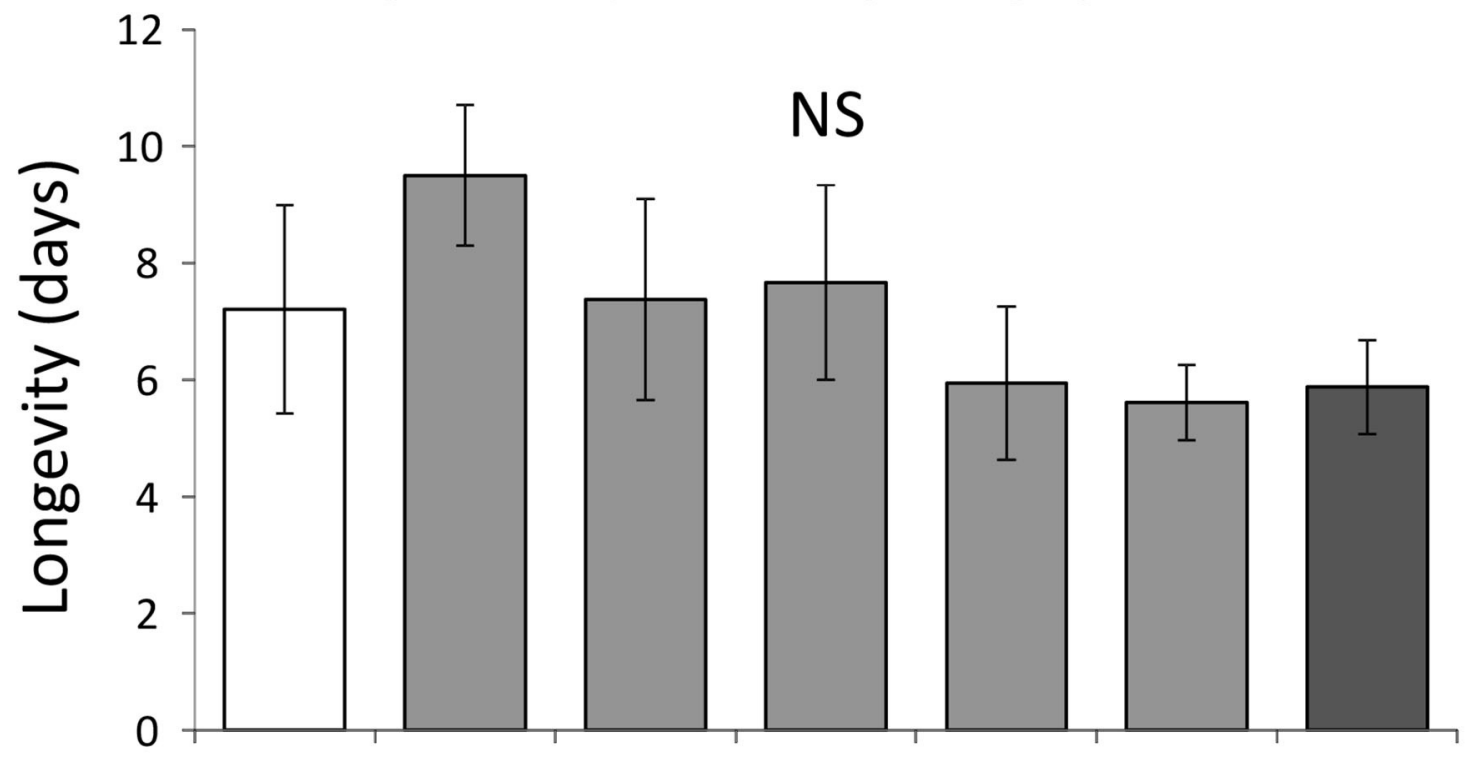

B

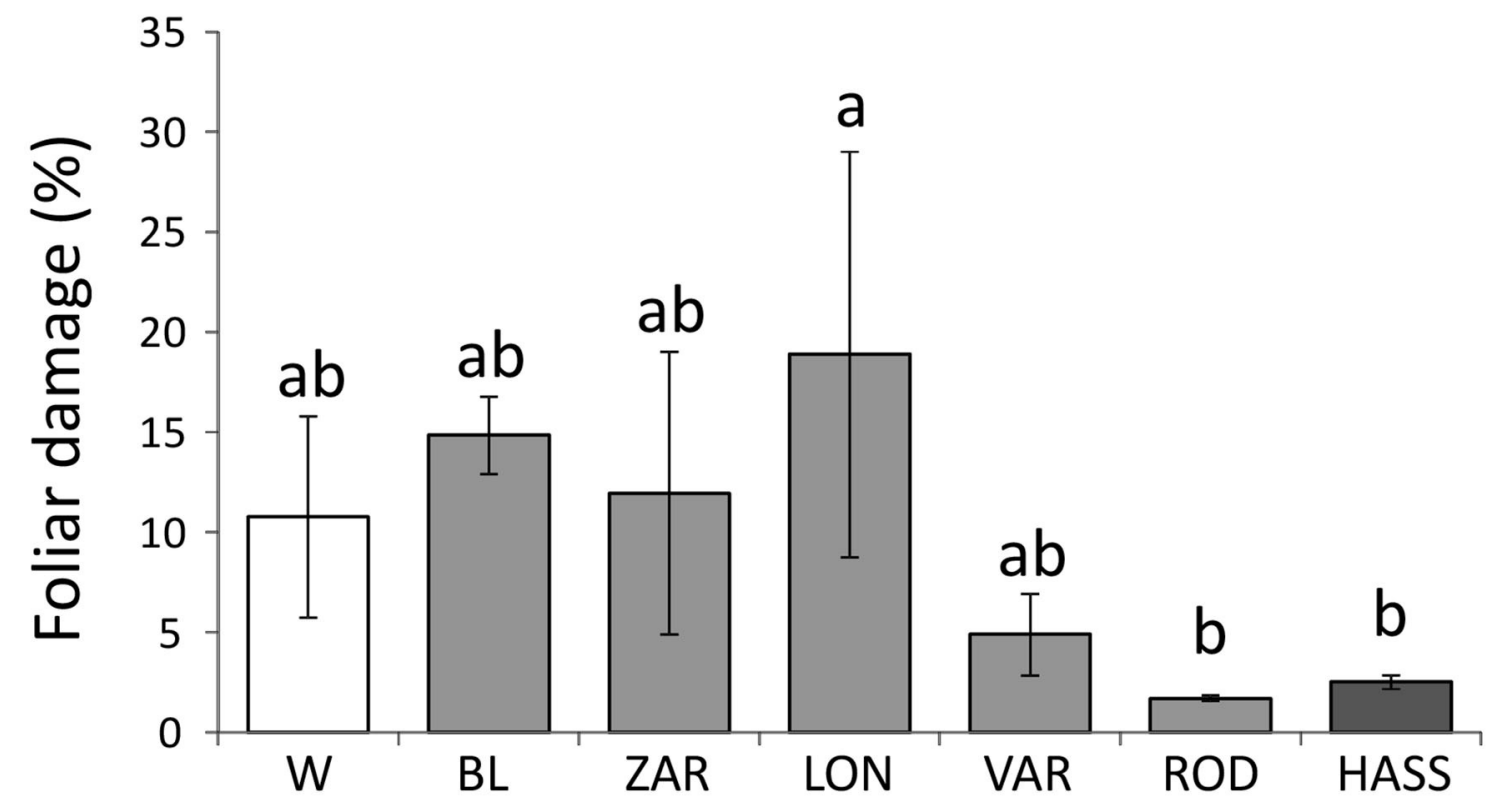

FIGURE 4 | Larval performance of the generalist fall armyworm, Spodoptera frugiperda, on wild, landrace, and cultivated "Hass" avocado (Persea americana) genotypes: larval longevity (A) and percent foliar damage (B). W = wild genotypes; landraces: BL = "Blanco," LON = "Lonjas," ZAR = "Zarcoli," VAR = "Vargas," and $\mathrm{ROD}=$ "Rodolfo." Bars are means $\pm \mathrm{SE}$. Different letters indicate significant differences among genotypes $(P \leq 0.05)$, according to Tukey's HSD post-hoc tests.

be better adapted to the secondary metabolites of their host plants than generalist herbivores (Stamp, 2003; Loxdale et al., 2011), although this prediction has been increasingly debated in recent years (Ali and Agrawal, 2012; Smilanich et al., 2016; Rothwell and Holeski, 2019). To our surprise, the generalist $S$. frugiperda performed better on some of the landraces that had higher phenolic content, whereas the specialist $C$. multifenestrata performed best on the cultivated "Hass." In fact, the performance of S. frugiperda was positively correlated with total phenolics on leaves, whereas the performance of C. multifenestrata was negative correlated with total phenolics. Previous studies showed a higher performance of generalist and non-coevolved herbivores 


\section{A}

\section{Copaxa multifenestrata}
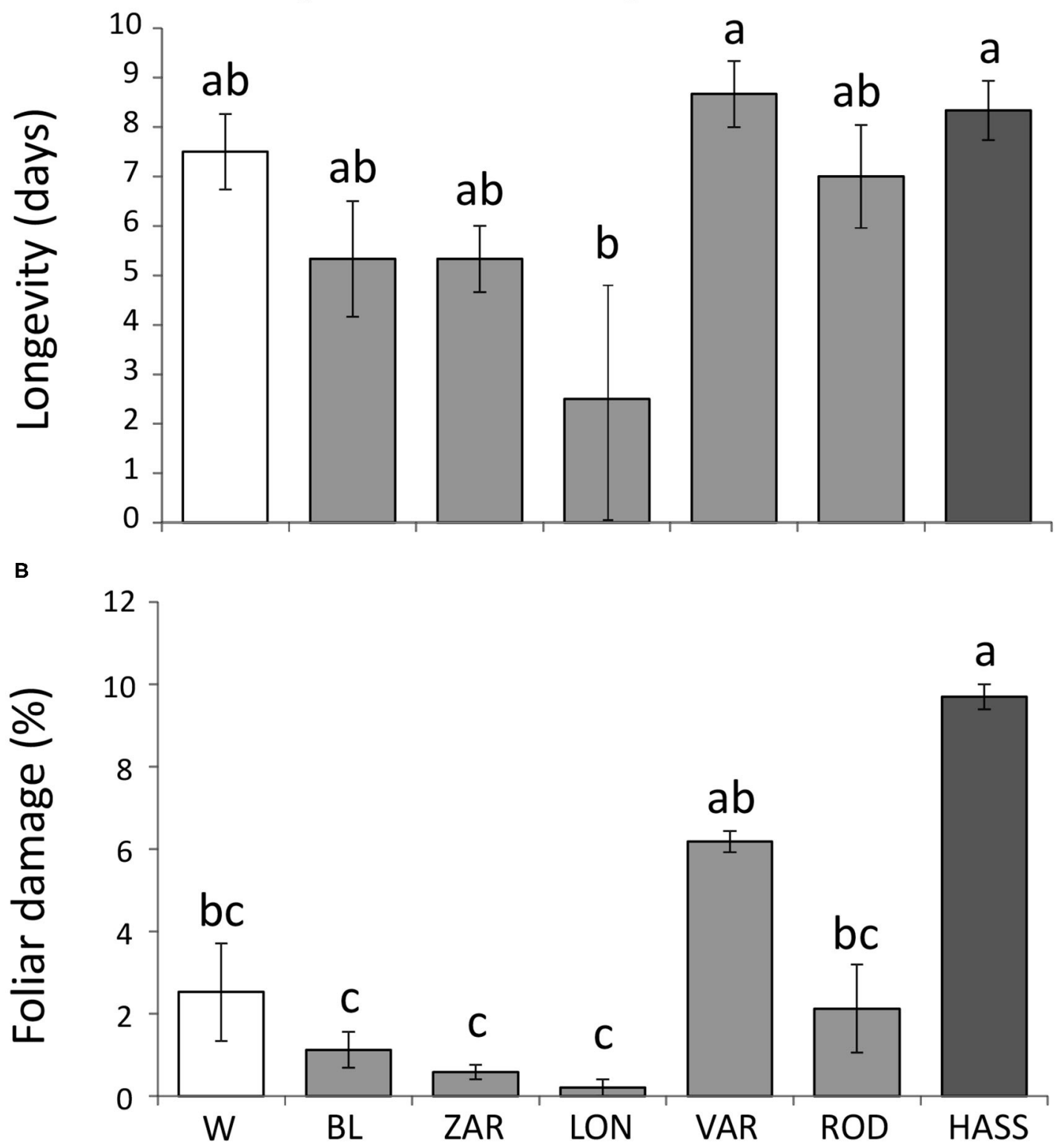

FIGURE 5 | Larval performance of the specialist avocado moth Copaxa multifenestrata on wild, landrace, and cultivated "Hass" avocado (Persea americana) genotypes: larval longevity (A) and percent foliar damage (B). W = wild genotypes; landraces: BL = "Blanco," LON = "Lonjas," ZAR = "Zarcoli," VAR = "Vargas," and $\mathrm{ROD}=$ "Rodolfo." Bars are means $\pm \mathrm{SE}$. Different letters indicate significant differences among genotypes $(P \leq 0.05)$, according to Tukey's HSD post-hoc tests.

on cultivated plants than on their wild counterparts (Gols et al., 2008; Gaillard et al., 2018; Hernandez-Cumplido et al., 2018). However, Chacón-Fuentes et al. (2015) found that Chilesia rudis Butler (Lepidoptera: Arctiidae), a native insect herbivore, performs better on wild ancestors of murtilla ( $U$. molinae) than on cultivated plants. Thus, crop domestication affects the performance of herbivores in various ways likely depending on their life histories. We only tested the effects of domestication in avocado on leaf defenses and resistance against folivores; further studies are needed to test if avocado domestication affects fruit defenses and resistance against frugivorous pests.

Several factors could be responsible for the opposite effects of phenolics (and domestication) on generalist and specialist herbivores in avocado. For instance, herbivores might prefer hosts that reduce their risk of predation or parasitism (Volf et al., 2015), as stated by the "enemy-free space" hypothesis (Jeffries and Lawton, 1984). An increased production of "Hass" avocados may have affected host use by the specialist C. multifenestrata, 
TABLE 1 | Correlation between plant reproductive/growth traits, plant defenses, and insect performance parameters.

\begin{tabular}{lllcc}
\hline Parameter tested & Variable 1 & Variable 2 & $\boldsymbol{R}^{\mathbf{2}}$ & $\boldsymbol{P}_{\text {-value }}$ \\
\hline Reproductive & Fruit length & Seed length & 0.580 & $<\mathbf{0 . 0 0 1}$ \\
Traits & Fruit width & Seed length & 0.003 & 0.605 \\
& Fruit length & Seed width & 0.005 & 0.492 \\
& Fruit width & Seed width & 0.261 & $<\mathbf{0 . 0 0 1}$ \\
Growth trait & Plant size & Fruit length & 0.061 & $\mathbf{0 . 0 2 1}$ \\
& Plant size & Fruit width & 0.006 & 0.491 \\
& Plant size & Seed length & 0.051 & $\mathbf{0 . 0 3 4}$ \\
& Plant size & Seed width & 0.006 & 0.496 \\
Leaf defenses & Total phenolics & Fruit length & 0.067 & 0.130 \\
& Total phenolics & Fruit width & 0.093 & 0.073 \\
& Total phenolics & Seed length & 0.140 & $\mathbf{0 . 0 2 6}$ \\
& Total phenolics & Seed width & 0.078 & 0.102 \\
Generalist & Total phenolics & Plant size & 0.001 & 0.838 \\
Spodoptera & Larval longevity & Total phenolics & 0.159 & 0.693 \\
frugiperda & Larval mass & Total phenolics & 0.204 & $\mathbf{0 . 0 2 6}$ \\
Specialist & Foliar damage & Total phenolics & 0.132 & 0.079 \\
Copaxa & Larval longevity & Total phenolics & -0.257 & $\mathbf{0 . 0 2 5}$ \\
multifenestrata & Larval mass & Total phenolics & 0.066 & 0.284 \\
& Foliar damage & Total phenolics & -0.208 & $\mathbf{0 . 0 4 9}$
\end{tabular}

${ }^{a}$ Numbers in bold indicate statistically significant correlations $(\alpha=0.05)$.

making it better adapted to them and reducing their ability to attack other hosts like the landraces. In fact, anecdotally, avocado farmers believe that feeding by the specialist $C$. multifenestrata might benefit "Hass" plants by causing tree crown thinning, which allows more sunlight penetration through the canopy that reduces disease incidence due to a decrease in moisture. Also, competition between specialist and generalist herbivores could have shaped the patterns in host-plant use (Barrett and Heil, 2012). Further studies are needed, particularly under field (natural) conditions, to test these hypotheses.

In summary, our study provides no clear support for the "plant domestication-reduced defense" hypothesis in avocado because domesticated plants (intermediate landraces and modern "Hass") were not consistently less resistant to herbivores than their wild ancestors. Contrary to our expectations, we found that the generalist $S$. frugiperda performs better in landraces that tended to have higher phenolic content, whereas the specialist $C$. multifenestrata performs better in "Hass" and wild genotypes that had lower phenolic content. It is clear that "Hass" was not selected

\section{REFERENCES}

Abbo, S., Pinhasi van-Oss, R., Gopher, A., Saranga, Y., Ofner, I., and Peleg, Z. (2014). Plant domestication versus crop evolution: a conceptual framework for cereals and grain legumes. Trends Plant Sci. 19, 351-360. doi: 10.1016/j.tplants.2013.12.002

Ali, J. G., and Agrawal, A. A. (2012). Specialist vs. generalist insect herbivores and plant defense. Trends Plant Sci. 17, 293-302. doi: 10.1016/j.tplants.2012.02.006 for resistance traits against herbivores but instead for traits related to fruit marketing (i.e., improved quantity, quality [taste], uniformity in size, and seasonal distribution/transportation) (Galindo-Tovar et al., 2008), which has resulted in plants with a slow growth rate, low germination, low levels of secondary metabolites (i.e., phenolics), and low resistance against $C$. multifenestrata. This low resistance is consistent with farmer reports of C. multifenestrata causing up to $60 \%$ damage in some regions, such as in Chilpancingo (Guerrero State, Mexico), and negatively affecting fruit production (J. Pérez, pers. com.). Due to these domestication syndromes, "Hass" plants have limited survival and growth in natural habitats. Based on our study, avocado landraces could be considered for the development of new, or the improvement of existing, varieties through breeding or grafting due to their improved agronomic characteristics; although, caution is needed because they might be more susceptible to generalist herbivores. This study provides the first evidence of variation among avocado genotypes on growth/reproductive and resistance traits across a domestication gradient that will be useful for future breeding programs and the conservation of the genotypic diversity in this crop.

\section{DATA AVAILABILITY STATEMENT}

The raw data supporting the conclusions of this article will be made available by the authors, without undue reservation.

\section{AUTHOR CONTRIBUTIONS}

JH-C, CR-S, SA-P, and AC-C conceptualized and designed the study. SM, PG-F, and CR-R collected data. JH-C and CR-S analyzed the data and wrote the first draft of the article. All authors read and edited the article.

\section{FUNDING}

This work was funded by a grant from the Universidad Nacional Autónoma de México (UNAM-PAPIIT IA202918) to JH-C and Hatch projects (Nos. NJ08252 and NJ08140) to CR-S.

\section{ACKNOWLEDGMENTS}

Thanks to Ivan Castellanos, Jaime Solis, Paulina Corona, Violeta Jímenez, Eduardo Jimenez, Enrique Llanos-Romero, Beatriz Zuñiga Ruíz, and Araceli Romero for their help in the laboratory and field. 
Barrett, L. G., and Heil, M. (2012). Unifying concepts and mechanisms in the specificity of plant-enemy interactions. Trends Plant Sci. 17, 282-292. doi: 10.1016/j.tplants.2012.02.009

Bautista, L. A., Parra, R. F., and Espinosa-Garcia, F. J. (2012). Efectos de la Domesticación de Plantas en la Diversidad Fitoquímica. Temas Sel. en Ecol. Química insectos. (El Colegio de 1 Frontera Sur. Mexico), 446.

Benrey, B., Callejas, A., Rios, L., Oyama, K., and Denno, R. F. (1998). The effects of domestication of Brassica and Phaseolus on the interaction between phytophagous insects and parasitoids. Biol. Control. 11, 130-140. doi: 10.1006/bcon.1997.0590

Brown, T. A., Jones, M. K., Powell, W., and Allaby, R. G. (2009). The complex origins of domesticated crops in the fertile crescent. Trends Ecol. Evol. 24, 103-109. doi: 10.1016/j.tree.2008.09.008

Chacón-Fuentes, M., Parra, L., Rodriguez-Saona, C., Seguel, I., Ceballos, R., and Quiroz, A. (2015). Domestication in murtilla (Ugni molinae) reduced defensive flavonol levels but increased resistance against a native herbivorous insect. Environ. Entomol. 44, 627-637. doi: 10.1093/ee/nvv040

Chaudhary, B. (2013). Plant domestication and resistance to herbivory. Int. J. Plant Genomics. 2013, 163-172. doi: 10.1155/2013/572784

Chen, Y. H., Gols, R., and Benrey, B. (2015). Crop domestication and its impact on naturally selected trophic interactions. Annu. Rev. Entomol. 60, 35-58. doi: 10.1146/annurev-ento-010814-020601

Coley, P. D., Bryant, J. P., and Chapin, F. S. (1985). Resource availability and plant antiherbivore defense. Science 230, 895-899. doi: 10.1126/science.230.4728.895

Evans, L. T. (1993). Crop Evolution, Adaptation and Yield. Cambridge: Cambridge University Press.

Gaillard, M. D. P., Glauser, G., Robert, C. A. M., and Turlings, T. C. J. (2018). Fine-tuning the "plant domestication-reduced defense" hypothesis: specialist vs. generalist herbivores. New Phytol. 1, 355-366. doi: 10.1111/nph.14757

Galindo-Tovar, M. E., Ogata-Aguilar, N., and Arzate-Fernández, A. M. (2008). Some aspects of avocado (Persea americana Mill.) diversity and domestication in Mesoamerica. Genet. Resour. Crop Evol. 55, 441-450. doi: 10.1007/s10722-007-9250-5

Gepts, P. (2004). Crop domestication as a long-term selection experiment. Plant Breed. Rev. 24, 1-44. doi: 10.1002/9780470650288.ch1

Giovanelli, G., and Buratti, S. (2009). Comparison of polyphenolic composition and antioxidant activity of wild Italian blueberries and some cultivated varieties. Food Chem. 4, 903-908. doi: 10.1016/j.foodchem.2008.06.066

Gols, R., Bukovinszky, T., Van Dam, N. M., Dicke, M., Bullock, J. M., and Harvey, J. A. (2008). Performance of generalist and specialist herbivores and their endoparasitoids differs on cultivated and wild Brassica populations. J. Chem. Ecol. 34, 132-143. doi: 10.1007/s10886-008-9429-z

Harborne, J. B. (2000). Arsenal for survival: secondary plant products. Taxon 49, 435-449. doi: 10.2307/1224343

Herms, D. A., and Mattson, W. J. (1992). The dilemma of plants: to grow or defend. Q. Rev. Biol. 67, 283-335. doi: 10.1086/417659

Hernandez-Cumplido, J., Giusti, M. M., Zhou, Y., Kyryczenko-Roth, V., Chen, Y. H., and Rodriguez-Saona, C. (2018). Testing the "plant domestication-reduced defense" hypothesis in blueberries: the role of herbivore identity. Arthropod. Plant. Interact. 12, 483-493. doi: 10.1007/s11829-018-9605-1

Jardon-Borbolla, L., Alavez, V., Mendez, V., Piñero, D., and Wegier, A. (2013). Análisis para la determinación de los centros de origen, domesticación y diversidad genética del género Persea y la especie Persea americana (aguacate). (Informe final CONABIO, Mexico), 23.

Jeffries, M. J., and Lawton, J. H. (1984). Enemy free space and the structure of ecological communities. Biol. J. Linn. Soc. 23, 269-286. doi: 10.1111/j.1095-8312.1984.tb00145.x

Jones, D. A. (1998). Why are so many food plants cyanogenic? Phytochemistry 47, 155-162. doi: 10.1016/S0031-9422(97)00425-1

Koinange, E. M. K., Singh, S. P., and Gepts, P. (1996). Genetic control of the domestication syndrome in common bean. Crop Sci. 36, 1037-1045. doi: 10.2135/cropsci1996.0011183X003600040037x

Landon, A. J. (2009). Domestication and significance of Persea americana, the avocado, in Mesoamerica. Nebraska Anthropol. 4, 62-79.

Lindig-Cisneros, R., Benrey, B., and Espinosa-García, F. J. (1997). Phytoalexins, resistance traits, and domestication status in Phaseolus coccineus and Phaseolus lunatus. J. Chem. Ecol. 23, 1997-2011. doi: 10.1023/B:JOEC.0000006485.38713.8c
Loxdale, H. D., Lushai, G., and Harvey, J. A. (2011). The evolutionary improbability of "generalism" in nature, with special reference to insects. Biol. J. Linn. Soc. 103, 1-18. doi: 10.1111/j.1095-8312.2011.01627.x

Machado, B. B., Orue, J. P. M., Arruda, M. S., Santos, C. V., Sarath, D. S., Goncalves, W. N., et al. (2016). BioLeaf: a professional mobile application to measure foliar damage caused by insect herbivory. Comp. Electron. Agr. 129, 44-55. doi: 10.1016/j.compag.2016.09.007

Magnoler, A. (1970). A wheat germ medium for rearing of the gypsy moth Lymantria dispar L. Entomophaga 15, 401-406. doi: 10.1007/BF02370308

Makkar, H. P. S. (ed). (2003). "Measurement of total phenolics and tannins using folin-ciocalteu method," in Quantification of Tannins in Tree and Shrub Foliage. (Dordrecht: Springer), 49-51. doi: 10.1007/978-94-017-0273-7

Massei, G., and Hartley, S. E. (2000). Disarmed by domestication? Induced responses to browsing in wild and cultivated olive. Oecologia 122, 225-231. doi: 10.1007/PL00008850

Medina-Aguilar, O., Alvarado-Díaz, J., and Suazo-Ortuño, I. (2011). Herpetofauna de Tacámbaro, Michoacán, México. Rev. Mex. Biodivers. 82, 1194-1202. doi: 10.22201/ib.20078706e.2011.4.740

Meyer, R. S., Duval, A. E., and Jensen, H. R. (2012). Patterns and processes in crop domestication: an historical review and quantitative analysis of 203 global food crops. New Phytol. 196, 29-48. doi: 10.1111/j.1469-8137.2012.04253.x

Mikulic-Petkovsek, M., Slatnar, A., Stampar, F., and Veberic, R. (2012). HPLC-MSn identification and quantification of flavonol glycosides in 28 wild and cultivated berry species. Food Chem. 135, 2138-2146. doi: 10.1016/j.foodchem.2012.06.115

Miller, A. J., and Gross, B. L. (2011). From forest to field: perennial fruit crop domestication. Am. J. Bot. 98, 1389-1414. doi: 10.3732/ajb.1000522

Mithöfer, A., and Boland, W. (2012). Plant defense against herbivores: chemical aspects. Аnnu. Rev. Plant Biol. 63, 431-450. doi: 10.1146/annurev-arplant-042110-103854

Montezano, D. G., Specht, A., Sosa-Gómez, D. R., Roque-Specht, V. F., Sousa-Silva, J. C., Paula-Moraes, S. V., et al. (2018). Host plants of Spodoptera frugiperda (Lepidoptera: Noctuidae) in the Americas. African Entomol. 26, 286-300. doi: $10.4001 / 003.026 .0286$

Moreno, S., Rocha, A., Alvarado, M., Salgado, M., and Pinson, E. P. (2010). AGUACATE: Variedades, Cultivo y Producción en Nuevo León. primera ed. (NL: UANL), 49.

Pérez Álvarez, S., Ávila Quezada, G., and Coto Arbelo, O. (2015). Revisión bibliográfica El aguacatero (Persea americana Mill). Cultiv. Trop. 36, 111-123.

Perez-Salgado, J., Angel, M., Cayetano, M., Bernabe, T., and Perez, E. (2016). Efectividad biológica in vitro de Tagetes lucida CAV, Ricinus communis $\mathrm{L}$, Nicotiana glauca Graham, Amphipterygium adstringens Schltdl y el hongo Ganoderma lucidum Curtis en larvas de Copaxa multifenestrata HerrichSchaffer 1858. en aguacate. Entomol. Mex. 3, 255-261.

Pro-aguacate (2010). Guia técnica de aguacates de Michoacan, sabor y energía para todo el dia. (Mexico: APEAM-Proaguacate), 15.

Reyes-Alemán, J., Espíndola-Barquera, M., Barrientos, A., Campos, E., and Aguilar, J. J. (2009). Aguacate: variedades, selecciones y variedades criollas de uso común. (Sistema Nacional de Recursos Fitogenéticos para la alimentación y la agricultura- Red Aguacate), 14.

Rhoades, D. (1979). "Evolution of plant chemical defence against herbivores," in Herbivores: Their Interaction with Secondary Plant Metabolites. eds G. A. Rosenthal and D. H. Janzen (New York, NY: Academic Press), 3-54.

Rodriguez-Saona, C., Cloonan, K. R., Sanchez-Pedraza, F., Zhou, Y., Giusti, M. M., and Benrey, B. (2019). Differential susceptibility of wild and cultivated blueberries to an invasive frugivorous pest. J. Chem. Ecol. 45, 286-297. doi: 10.1007/s10886-018-1042-1

Rodriguez-Saona, C., Vorsa, N., Singh, A. P., Johnson-Cicalese, J., Szendrei, Z., Mescher, M. C., et al. (2011). Tracing the history of plant traits under domestication in cranberries: potential consequences on anti-herbivore defences. J. Exp. Bot. 62, 2633-2644. doi: 10.1093/jxb/erq466

Rosenthal, J. P., and Dirzo, R. (1997). Effects of life history, domestication and agronomic selection on plant defence against insects: evidence from maizes and wild relatives. Evol. Ecol. 11, 337-355. doi: 10.1023/A:1018420 504439

Rothwell, E. M., and Holeski, L. M. (2019). Phytochemical defences and performance of specialist and generalist herbivores: a meta-analysis. Ecol. Entomol. 45, 396-405. doi: 10.1111/een.12809 
SAGARPA (2011). Monografía de cultivos: Aguacate. (Subsecretaria de fomento a los agronegocios), 10.

Smartt, J., and Simmonds, N. (1995). Evolution of Crop Plants. (Longman: Cambridge University Press), 469.

Smilanich, A. M., Fincher, R. M., and Dyer, L. A. (2016). Does plant apparency matter? Thirty years of data provide limited support but reveal clear patterns of the effects of plant chemistry on herbivores. New Phytol. 210, 1044-1057. doi: $10.1111 /$ nph. 13875

Stamp, N. (2003). Out of the quagmire of plant defense hypotheses. Q. Rev. Biol. 78, 23-55. doi: 10.1086/367580

Turcotte, M. M., Turley, N. E., and Johnson, M. T. J. (2014). The impact of domestication on resistance to two generalist herbivores across 29 independent domestication events. New Phytol. 204, 671-681. doi: 10.1111/nph.12935

Volf, M., Hrcek, J., Julkunen-Tiitto, R., and Novotny, V. (2015). To each its own: differential response of specialist and generalist herbivores to plant defence in willows. J. Anim. Ecol. 84, 1123-1132. doi: 10.1111/1365-2656.12349

Whitehead, S. R., and Poveda, K. (2019). Resource allocation trade-offs and the loss of chemical defences during apple domestication. Ann. Bot. 123, 1029-1041. doi: $10.1093 / \mathrm{aob} / \mathrm{mcz} 010$

Whitehead, S. R., Turcotte, M. M., and Poveda, K. (2017). Domestication impacts on plant-herbivore interactions: a meta-analysis. Philos. Trans. R. Soc. B Biol. Sci. 372:20160034. doi: 10.1098/rstb.2016.0034
Wink, M. (1988). Plant breeding: importance of plant secondary metabolites for protection against pathogens and herbivores. Theor. Appl. Genet. 75, 225-233. doi: 10.1007/BF00 303957

Yamassaki, F. T., Campestrini, L. H., Zawadzki-Baggio, S. F., and Maurer, J. B. B. (2017). Avocado leaves: influence of drying process, thermal incubation, and storage conditions on preservation of polyphenolic compounds and antioxidant activity. Int. J. Food Prop. 20, 2280-2293. doi: $10.1080 / 10942912.2017 .136910$

Conflict of Interest: The authors declare that the research was conducted in the absence of any commercial or financial relationships that could be construed as a potential conflict of interest.

Copyright (c) 2021 Hernández-Cumplido, Rodriguez-Saona, Ruíz-Rodríguez, Guevara-Fefer, Aguirre-Paleo, Miranda Trejo and Callejas-Chavero. This is an openaccess article distributed under the terms of the Creative Commons Attribution License (CC BY). The use, distribution or reproduction in other forums is permitted, provided the original author(s) and the copyright owner(s) are credited and that the original publication in this journal is cited, in accordance with accepted academic practice. No use, distribution or reproduction is permitted which does not comply with these terms. 